\title{
Decreased RORC-dependent silencing of prostaglandin receptor EP2 induces autoimmune Th17 cells
}

\author{
David M. Kofler,,$^{1,2}$ Alexander Marson, ${ }^{3}$ Margarita Dominguez-Villar, ${ }^{1,2}$ Sheng Xiao, ${ }^{4}$ \\ Vijay K. Kuchroo, ${ }^{2,4}$ and David A. Hafler ${ }^{1,2}$

\begin{abstract}
1Departments of Neurology and Immunobiology, Yale School of Medicine, New Haven, Connecticut, USA.
2Broad Institute of Harvard University and Massachusetts Institute of Technology, Cambridge, Massachusetts, USA.

${ }^{3}$ Diabetes Center and Division of Infectious Diseases, Department of Medicine, UCSF, San Francisco, California, USA.

${ }^{4}$ Center for Neurologic Diseases, Brigham and Women's Hospital and Harvard Medical School, Boston, Massachusetts, USA.
\end{abstract}

\begin{abstract}
Prostaglandin E2 (PGE2) promotes Th17 expansion while otherwise inhibiting other $\mathrm{CD}^{+} \mathrm{T}^{\mathrm{T}}$ cell subsets. Here, we identified a PGE2-dependent pathway that induces pathogenic Th17 cells in autoimmune disease and is regulated by the transcription factor RORC. Compared with other $\mathrm{CD}^{+}$cell types from healthy subjects, there is a surprising lack of the prostaglandin receptor EP2 on Th17 cells; therefore, we examined the hypothesis that ROR $\gamma t$, which is highly expressed in Th17 cells, mediates EP2 downregulation. Chromatin immunoprecipitation followed by DNA sequencing revealed that ROR $\gamma \mathrm{t}$ binds directly to Ptger2 (the gene encoding EP2 receptor) in Th17 cells isolated from WT mice. In Th17 cells isolated from humans, RORC repressed EP2 by directly silencing PTGER2 transcription, and knock down of RORC restored EP2 expression in Th17 cells. Compared with Th17 cells from healthy individuals, Th17 cells from patients with MS exhibited reduced RORC binding to the PTGER2 promoter region, resulting in higher EP2 levels and increased expression of IFN- $\gamma$ and GM-CSF. Finally, overexpression of EP2 in Th17 cells from healthy individuals induced a specific program of inflammatory gene transcription that produced a pathogenic Th17 cell phenotype. These findings reveal that RORC directly regulates the effects of PGE2 on Th17 cells, and dysfunction of this pathway induces a pathogenic Th17 cell phenotype.
\end{abstract}

\section{Introduction}

Prostaglandin E2 (PGE2) plays an important role as an immune regulator, exerting immunosuppressive as well as immuneactivating functions (1-3), and genetic variants in the prostaglandin pathway are associated with the risk of developing MS $(4,5)$ and other autoimmune diseases $(6,7)$. The influence of PGE2 on $\mathrm{CD}^{+}$cells varies depending upon the $\mathrm{CD} 4^{+} \mathrm{T}$ cell subset, PGE2 concentration, and the activation status of the cell (2). While PGE2 can suppress T cell proliferation and IFN- $\gamma$ production in mature Th1 cells (8-10), it has recently been reported that PGE2 facilitates Th1 cell differentiation through EP2 and EP4 receptors when accompanied by strong $T$ cell receptor signaling (11). Furthermore, PGE2 induces Th17 cell expansion and promotes experimental autoimmune encephalomyelitis (EAE), an animal model of MS (11-14). While there are increases in Th17 cell expansion mediated through IL-23 and IL-1 receptor upregulation (13) in Th17-polarized T cells, PGE2 inhibits IL-17 in naive $\mathrm{T}$ cells (15). The mechanism for these divergent effects of PGE2 on T cell function and how the prostaglandin pathways influence autoimmune diseases are not known.

PGE2 binds to the G protein-coupled receptors EP1, EP2, EP3, and EP4 $(11,16)$. Among these receptors, only EP2 and EP4 are significantly expressed on activated $\mathrm{CD} 4^{+} \mathrm{T}$ cells $(13,17)$. While it has been shown that both receptors are involved in Th17 cell expansion as well as in the inhibition of Th17 cell induction $(13,15)$, it is unknown how EP2 and EP4 and downstream signaling events

Conflict of interest: The authors have declared that no conflict of interest exists. Citation for this article: J Clin Invest. 2014;124(6):2513-2522. doi:10.1172/JCI72973. regulate $\mathrm{CD}^{+} \mathrm{T}$ cell lineage development. Suppression of IL-10 and IFN- $\gamma$ production in Th17 cells is predominantly mediated through EP4 signaling (13), and furthermore, EP4 activation is responsible for PGE2-induced immune inflammation and disease progression in EAE $(11,14)$. The inhibitory effect of PGE2 on Th1 cells is concentration dependent, as lower concentrations of PGE2 have been shown to facilitate Th1 differentiation (11). It has also been reported that PGE2 decreases the frequency of IFN- $\gamma^{-} \mathrm{CD}^{+}$ $T$ cells, but not the frequency of IL-17+IFN- $\gamma^{+}$double-positive $\mathrm{CD} 4^{+} \mathrm{T}$ cells during Th17 cell differentiation $(12,13)$.

MS is an autoimmune disease that is characterized by perivenular infiltrates of $\mathrm{CD}^{+}$and $\mathrm{CD}^{+} \mathrm{T}$ cells in the CNS white matter and meninges, with demyelinating lesions and loss of axons in both white and gray matter $(18,19)$. The risk of developing MS is significantly increased in genetically susceptible subjects (5). Our recent genome-wide association studies (GWAS) have identified 2 risk alleles in PTGER4, the gene for the PGE2 receptor EP4 $(4,5)$. Previous reports have shown that PGE2 concentrations in the serum and in the cerebrospinal fluid of MS patients are elevated $(20,21)$. However, the role of PGE2 in the etiology of MS remains unknown. Th1 and Th17 cells play an important role in the development of EAE and are implicated in MS pathology $(22-25)$. Moreover, we have recently shown that the most pathogenic Th17 cells are those expressing Ifng, Stat4, Tbx21, Il22, Csf2, and Runx 3 genes, with decreases in $I l 10$ and $A b r$ (26). Given the significant influence of PGE2 on Th17 cells and the occurrence of MS-associated SNPs in PGE2 receptors, we sought to investigate the role of EP2 and EP4 receptors in Th17 cells from patients with MS and in those from healthy individuals. 

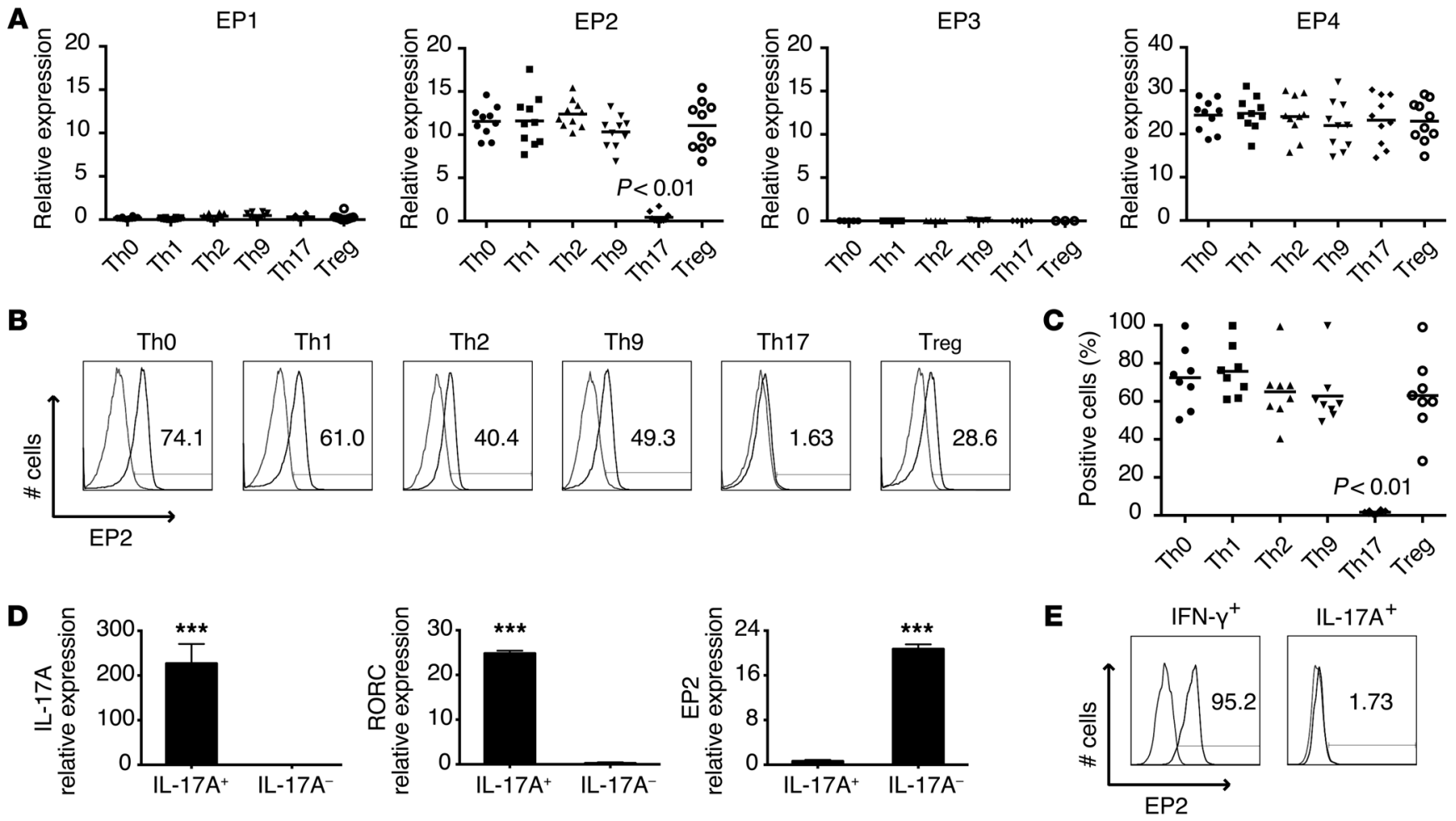

Figure 1

Prostaglandin receptor expression in human CD4+ $\mathrm{T}$ cell subsets. (A) Quantitative RT-PCR analysis of EP1, EP2, EP3, and EP4 expression in distinct CD4 ${ }^{+}$T cell subsets. $P$ was calculated by 1 -way ANOVA test. $n=10$ individual donors. CD4 ${ }^{+}$subsets were differentiated from naive CD4 ${ }^{+}$cells in the presence of $2.5 \mu \mathrm{g} / \mathrm{ml}$ anti-CD3 antibodies, $1 \mu \mathrm{g} / \mathrm{ml}$ anti-CD28 antibodies, and the respective cytokines required for the induction of specific CD4+ subsets. Representative example (B) and cumulative results (C) of flow cytometric analysis of EP2 expression in Th0, Th1, Th2, Th9, Th17, and Tregs. $P$ was calculated by 1-way ANOVA test. $n=8$ individual donors. (D) IL-17A, RORC, and EP2 expression in ex vivo-isolated IL-17+CD4+ T cells and IL-17-CD4+ $T$ cells. Cells were sorted by FACSAria based on cell surface expression of IL-17. ${ }^{\star \star \star} P<0.001$. $P$ was calculated by an unpaired Student's $t$ test; mean \pm SEM. $n=10$ individual donors. (E) Representative example of flow cytometric analysis of EP2 expression in IFN- $\gamma^{+}$and IL-17+ memory CD4 $+\mathrm{T}$ cells. Cells were analyzed for EP2 expression directly after ex vivo isolation without prior purification by FACSAria cell sorting.

Here, we examined the role of PGE2 in the development of potentially pathogenic Th17 cells and observed loss of PGE2 receptor EP2 expression on Th17 cells mediated by RORC, which directly silenced the EP2 receptor PTGER2 gene. In contrast, expression of EP2 was partly restored on Th17 cells from patients with MS due to diminished PTGER2 silencing. We observed increased proliferative responses with lower signal strengths induced by anti-CD3 cross-linking, and these responses correlated with both increased EP2 expression and GM-CSF production by Th17 cells in patients. Finally, the binding of RORC to PTGER2 in Th17 cells was decreased in MS patients as compared with those from healthy controls when cells were stimulated with the same strength of $\mathrm{T}$ cell receptor signaling. These findings indicate that EP2 expression on MS Th17 cells is mediated in part by the lower $\mathrm{T}$ cell-signaling threshold observed in human autoimmune disease (27). Our results offer a mechanism by which EP2 downregulation protects normal Th17 cells from PGE2mediated IFN- $\gamma$ and GM-CSF induction and indicate a role of the PGE2 pathway in human autoimmune disease.

\section{Results}

EP2 expression is specifically suppressed in Th17 cells. In order to investigate the role of PGE2 receptors in patients with MS, we first analyzed the expression of PGE2 receptors in nor- mal human Th17 cells and other $\mathrm{CD}^{+} \mathrm{T}$ cell subsets. Naive

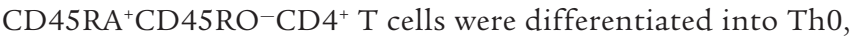
Th1, Th2, Th9, or Th17 cells and cultured for 4 days in the presence of anti-CD3 and CD28 mAbs and the respective cytokines. $\mathrm{CD} 4^{+} \mathrm{CD} 25^{\text {hi }} \mathrm{CD} 127^{\text {lo }} \mathrm{FOXP} 33^{\text {hi }}$ Tregs were also analyzed ex vivo for PGE2 receptor expression. Efficient differentiation into $\mathrm{CD}^{+} \mathrm{T}$ cell subsets was verified by transcription factor analysis. Th17 cells expressed RORC, RORA, AHR, IL1R1, IL23R, CCR6, IL17A, IL17F, and IL22 (Supplemental Figure 1A; supplemental material available online with this article; doi:10.1172/ JCI72973DS1) and produced IL-17A (Supplemental Figure 1, $\mathrm{B}-\mathrm{D})$. In contrast to all other $\mathrm{CD}^{+} \mathrm{T}$ cell subsets, Th17 cells from healthy individuals did not express EP2 (Figure 1, A-C), even after stimulation with high concentrations of anti-CD3 antibodies (Supplemental Figure 2). To verify our results in in vivo primed Th17 cells, we analyzed EP2 expression in highly purified Th17 cells obtained by sorting based on IL-17A cell surface expression. These IL-17A ${ }^{+}$cells expressed high levels of RORC and almost undetectable levels of EP2 (Figure 1D). Flow cytometric analysis of ex vivo isolated IL-17A $\mathrm{A}^{+}$or IFN- $\gamma^{+}$memory $\mathrm{CD}^{+} \mathrm{T}$ cells showed high expression of EP 2 in IFN $-\gamma^{+} \mathrm{CD} 4^{+}$ $\mathrm{T}$ cells and very low expression in IL-17A $\mathrm{A}^{+} \mathrm{CD} 4^{+} \mathrm{T}$ cells (Figure 1E). Expression of other PGE2 receptors did not differ between 
A

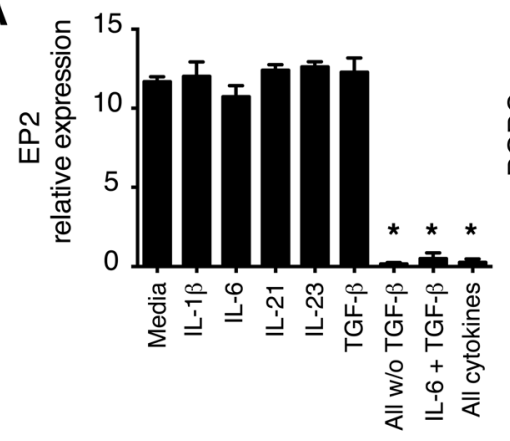

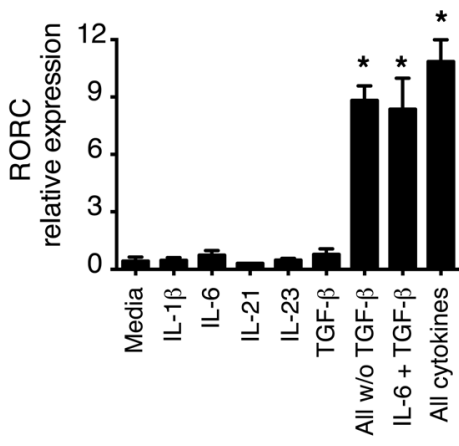

B

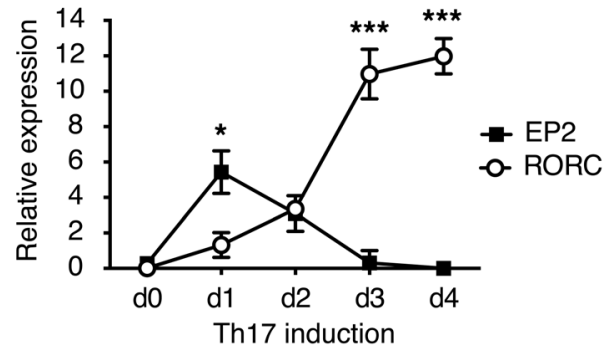

Figure 2

Expression of EP2 negatively correlates with RORC expression in CD4+ $T$ cells. (A) Naive CD45RA+CD45RO-CD4+ ${ }^{+}$cells from healthy controls were cultured with the indicated cytokines. EP2 and RORC expression was analyzed by RT-PCR. ${ }^{*}<0.01$ by 1 -way ANOVA (mean \pm SEM; $n=10$ ). (B) Time kinetics of EP2 and RORC expression in Th17 cells induced from naive CD45RA+CD45RO-CD4+ T cells. ${ }^{* *} P<0.0001$ by an unpaired Student's $t$ test comparing EP2 expression at 0 and 24 hours; mean \pm SEM. $n=5$.

different $\mathrm{CD}^{+} \mathrm{T}$ subsets (Figure $\left.1, \mathrm{~A}-\mathrm{C}\right)$. EP2 downregulation in Th17 cells was therefore the only variation of PGE2 receptor expression we observed in the different $\mathrm{CD}^{+} \mathrm{T}$ cell subsets.

EP2 negatively correlates with RORC in $C D 4^{+} T$ cells. Differentiation of human Th17 cells is induced by $\mathrm{T}$ cell activation in the presence of TGF- $\beta$ and the Th17 cell-inducing cytokines IL-1 $\beta$, IL-6, IL-21, or IL-23 (28) depending on whether they are naive or memory $\mathrm{CD} 4^{+} \mathrm{T}$ cells. To verify whether EP2 downregulation is caused by a specific cytokine or by a combination of Th17-inducing cytokines, we cultured naive $\mathrm{CD}^{+} \mathrm{T}$ cells with IL-1 $\beta$, IL-6, IL-21, IL-23, or TGF- $\beta$ alone or with a combination of these cytokines for 4 days. While the expression of EP2 was suppressed by a combination of Th17 cell-inducing cytokines, none of these cytokines alone was sufficient to downregulate EP2 expression (Figure 2A). The combination of TGF- $\beta$ and IL- 6 was also able to induce RORC and resulted in highly efficient downregulation of EP2 (Figure 2A). However, we found that TGF- $\beta$ was not required for the suppression of EP2 expression in Th17 cells (Figure 2A). Efficient induction of RORC under Th17-skewing conditions highly correlated with EP2 downregulation $(P<0.001)$. The presence of IL-17A in the cell culture had no influence on EP2 expression (data not shown). After an initial increase during the first 24 hours, we observed that expression of EP2 decreased continuously during Th17 cell differentiation with a combination of TGF- $\beta$, IL-1 $\beta$, IL- 6 , IL- 21 , and IL-23. After 72 hours of activation, EP2 expression was absent in Th17 cells, showing a strong negative correlation between the induction of RORC and EP2 downregulation (Figure 2B). We did not find any strong correlation between EP2 expression and other transcription factors, including T-bet, GATA3, FOXP3, and IRF4 (Supplemental Figure 3).

$E P 2$ is directly silenced by RORC. With the strong correlation between RORC induction and EP2 suppression, we hypothesized that RORC directly interacts with PTGER2, the gene encoding for the EP2 receptor. We used ChIP sequencing to evaluate the binding properties of RORyt to Ptger2 in Th17 cells from C57BL/6 WT mice or ROR $\gamma \mathrm{t}^{-/-}$knockout mice. We found that ROR $\gamma \mathrm{t}$ bound to the promoter region of Ptger 2 and, more strongly, to a second region at the $3^{\prime}$ end of the gene (Figure 3A). Th17 cells from ROR $\gamma \mathrm{t}^{-/-}$knockout mice were used as a specificity control (Supplemental Figure 4A). We observed no binding to Ptger 2 in ROR $\mathrm{tt}^{-/}$- Th17 cells.
To directly investigate the mechanism for loss of the EP2 receptor in RORC-expressing Th17 cells, we used siRNA for specific knock down of RORC in human Th17 cells. We cultured naive $\mathrm{CD}^{2} \mathrm{RA}^{+} \mathrm{CD} 45 \mathrm{RO}^{-} \mathrm{CD}^{+} \mathrm{T}$ cells from healthy individuals in the presence of TGF- $\beta$, IL- $1 \beta$, IL-6, IL-21, and IL-23 for 3 days. Th 17 cells were then transduced with either RORC-specific siRNA or mock siRNA and cultured for an additional 2 days. Efficiency of RORC knock down was controlled by Western blotting (Supplemental Figure 4B). RORC knock down restored EP2 expression, while EP2 remained repressed in mock-transduced Th17 cells (Figure 3B). To further evaluate the possibility that RORC represses transcription of EP2 by directly silencing PTGER2, we transfected naive $\mathrm{CD}^{+} \mathrm{T}$ cells with a luciferase reporter construct under the control of the PTGER2 promoter. Transfection of the reporter plasmid, together with a construct encoding RORC, resulted in substantial and dose-dependent repression of luciferase activity, showing that EP2 expression is directly silenced by RORC (Figure 3C).

EP2 overexpression induces pathogenic gene signature in Th17 cells. EP2 is upregulated on $\mathrm{CD}^{+} \mathrm{T}$ cells upon TCR stimulation (29). We therefore studied the influence of TCR signaling strength on RORC-mediated EP2 downregulation. Naive CD4 ${ }^{+} \mathrm{T}$ cells transfected with a RORC expression plasmid were cultured under nonskewing (Th0) conditions with IL-2 and different concentrations of anti-CD3 antibodies. We found that strong TCR stimulation was in part able to restore EP2 expression in RORC-expressing $\mathrm{CD}^{+} \mathrm{T}$ cells (Figure 4A). Increased EP2 expression was not due to a loss of RORC expression (Figure 4B). These findings indicate that strong TCR signaling can partially overcome RORC-mediated downregulation of EP2 expression.

Since EP2 expression is suppressed in Th17 cells, we wished to further investigate potential effects of EP2 signaling on Th17 cells. We transfected Th17 cells with an EP2 expression plasmid, resulting in significant EP2 expression as compared with that in mock-transfected cells (Supplemental Figure 5, A and B). Transcriptional analysis of EP2-overexpressing Th17 cells showed an increase in IFNG, CSF2, IL22, TBX21, RUNX3, and STAT4 expression upon activation with butaprost (Figure 5, A and B). Butaprost is a structural analog of PGE2 and a selective agonist of the EP2 receptor. The expression of IL-10 and AHR was diminished in EP2-expressing Th17 cells following EP2-specific activation. We 
A

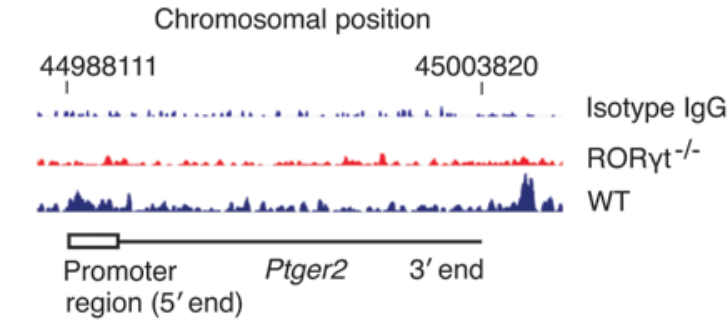

B
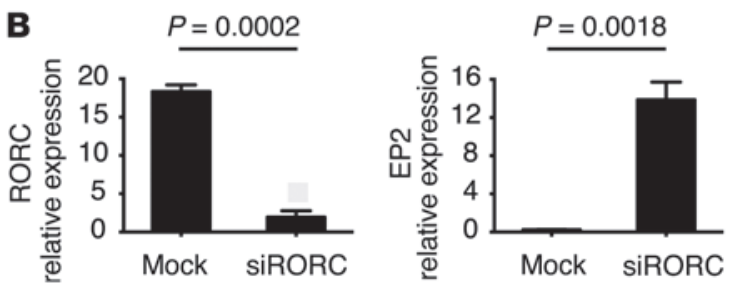

Figure 3

PTGER2 is directly silenced by RORC. (A) Th17 cells were induced from naive CD4+ ${ }^{+}$cells from C57BL/6 WT mice or ROR $\gamma \mathrm{t}^{-/-}$knockout mice, and binding of ROR $\gamma \mathrm{t}$ to Ptger2 on chromosome 14 was analyzed by ChIP-seq. Isotype IgG was used to control unspecific binding. (B) Knock down of RORC in Th17 cells by specific siRNA or nonsense control siRNA. Human Th17 cells were induced from naive CD4 ${ }^{+}$T cells, and RORC and EP2 expression was analyzed by RT-PCR. $P$ was calculated by an unpaired Student's $t$ test; mean \pm SEM. $n=3$. (C) Transcriptional silencing of PTGER2 by RORC was quantified by measuring the luciferase activity in $\mathrm{CD}^{+}{ }^{+} \mathrm{T}$ cells transfected with various concentrations of RORC expression plasmids and reporter constructs containing the firefly luciferase gene under the control of the PTGER2 promoter. Results are presented relative to Renilla luciferase activity (cotransfected control). ${ }^{*} P=0.0154,{ }^{\star \star} P=0.0063$, and ${ }^{* \star \star} P=0.0034$ by an unpaired Student's $t$ test; mean \pm SEM. $n=3$.

did not observe butaprost-induced changes in gene expression in mock-transfected Th17 cells. The expression of RORC and IL-17A was not affected by EP2 overexpression (Figure 5A), suggesting that there is no feedback loop between EP2 signaling and RORC expression. EP2-overexpressing Th17 cells produced significantly more IFN- $\gamma$ and GM-CSF upon activation with an EP2-specific agonist (Figure 5C). In contrast, we found that IL-10 secretion was diminished in EP2-overexpressing Th17 cells as compared with that observed in mock-transfected cells.

EP2 is expressed in Th17 cells from patients with MS. As increased frequencies of IL-17A IFN- $\gamma^{+}$ double-positive $\mathrm{CD}^{+} \mathrm{T}$ cells are found during EAE development and in patients with MS (30), we investigated the correlation between EP2 expression and IFN- $\gamma$ induction in Th17 cells from untreated patients with relapsing-remitting MS (RRMS). Th17 cells were induced from naive CD45RA ${ }^{+} \mathrm{CD} 4^{+} \mathrm{T}$ cells from MS patients and healthy controls (Supplemental Figure 1, C and $\mathrm{D}$ ). We found that, in contrast to Th17 cells from healthy subjects, Th17 cells from patients with MS expressed EP2, albeit at lower levels than did non-Th17 cells (Figure 6, A-C). Activation with the EP2-specific agonist butaprost induced expansion of Th17 cells from $\mathrm{CD}^{+}$ CD45RO ${ }^{+}$memory $\mathrm{T}$ cells obtained from MS patients. The frequency of IL-17A+IFN- $\gamma^{+}$cells was significantly increased in the presence of EP2 agonist during expansion of Th17 cells from MS patients as compared with those from healthy individuals (Figure 6, D and E). In striking contrast, the EP4 agonist misoprostol had no influence on the frequency of IL-17A $\mathrm{A}^{+} \mathrm{IFN}-\gamma^{+} \mathrm{Th} 17$ cells in patients with MS and in healthy individuals. Moreover, EP2-specific activation during Th17 differentiation induced IFNG and CSF2 gene expression (Figure 7A) and GM-CSF secretion in Th17 cells from MS patients, while having no influence on Th17 cells from healthy individuals (Figure 7B).

We wished to explore the potential mechanism for EP2 expression on $\mathrm{CD}^{+} \mathrm{T}$ cells from patients with MS. Since increasing $\mathrm{T}$ cell receptor-signaling strength led to increases in EP2 expression (Figure 4), we investigated whether there were increases in the frequency of proliferating $\mathrm{CD} 4^{+}$cells in patients with MS as compared with the frequency in control subjects. Consistent with the activated state of CD4 cells in the circulation of MS patients (31), we observed increased proliferative responses with lower signal strengths induced by anti-CD3 cross-linking in patients (Figure 8A and Supplemental Figure 6A). Finally, we observed that the strength of $\mathrm{T}$ cell receptor signaling correlated with both increased EP2 expression in $\mathrm{CD}^{+}$cells (Figure $8 \mathrm{~B}$ ) and GM-CSF production by Th17 cells from MS patients (Supplemental Figure 6B). In contrast, the expression level of RORC did not differ between Th17 cells from MS patients and those from healthy individuals (Supplemental Figure 1E).

As the strength of $\mathrm{T}$ cell receptor signaling correlates with increased expression of EP2, we performed ChIP-PCR to directly determine the binding activity of ROR $\gamma$ to Ptger 2 in Th17 cells with increasing TCR signal strengths induced by increasing con-

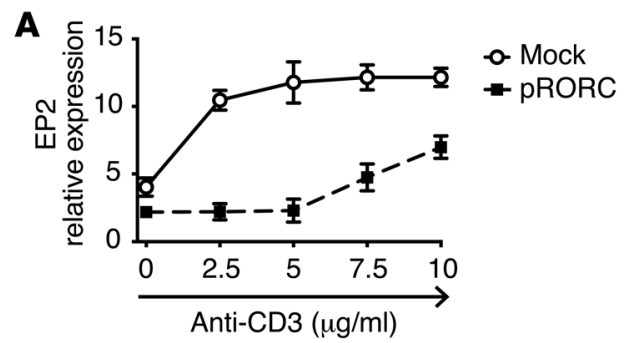

\section{Figure 4}

EP2 expression in CD4+ T cells is induced by TCR stimulation. (A) Strong TCR stimulation partly restored EP2 expression in RORC+CD4+ $\mathrm{T}$ cells. Naive $\mathrm{CD} 4+\mathrm{T}$ cells were transfected with a RORC expression plasmid and cultured with various concentrations of anti-CD3 antibodies under nonskewing (Th0) conditions. EP2 expression was analyzed and compared with EP2 expression in mock-transfected Th0 cells. $P=0.0006$ comparing EP2 expression at $2.5 \mu \mathrm{g}$ and $0 \mu \mathrm{g}$ anti-CD3 mAbs, and $P=0.0057$ comparing EP2 expression at $10 \mu \mathrm{g}$ and $0 \mu \mathrm{g}$ anti-CD3 $\mathrm{mAb}$; mean \pm SEM. $n=5$. (B) RORC expression levels were controlled in RORC-transfected Th0 cells. 
A
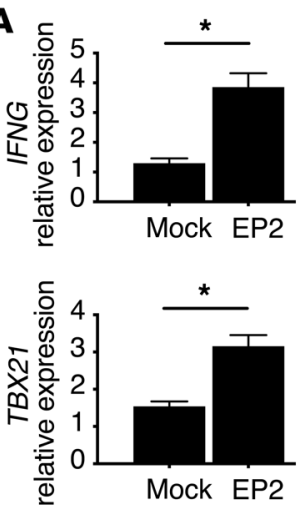
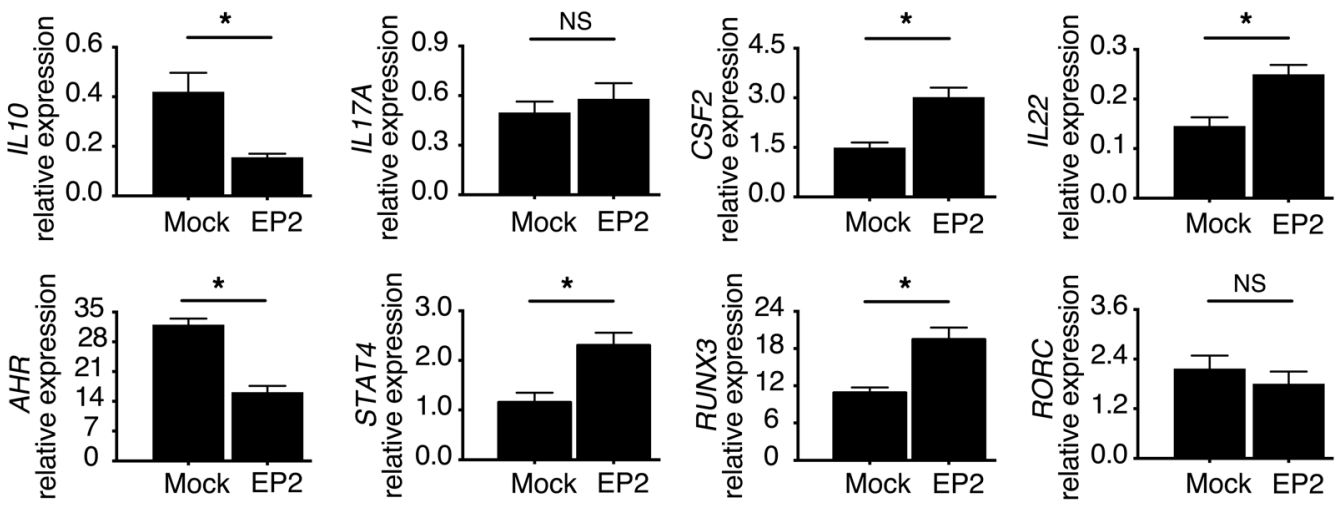

B

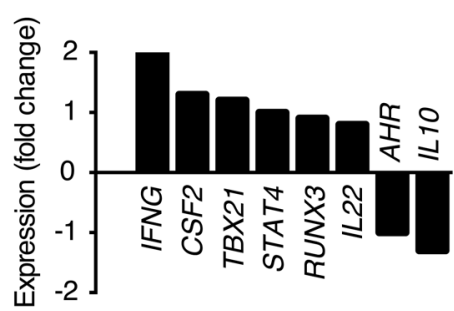

C

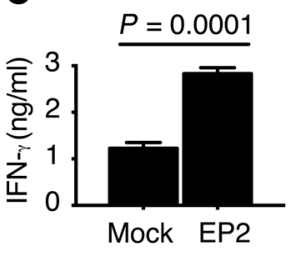

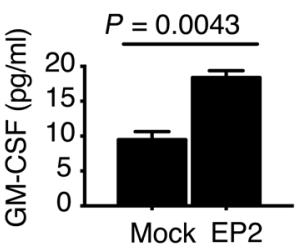

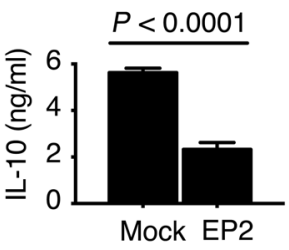

Figure 5

EP2 overexpression induces a pathogenic genotype in Th17 cells. (A) Quantitative RT-PCR analysis of genes in EP2-transfected Th17 cells and mock-transfected Th17 cells (mean $\pm \mathrm{SEM} ; n=5$ ). ${ }^{*} P<0.05$. (B) Fold changes in gene expression after treatment of EP2-transfected and mock-transfected Th17 cells with butaprost and $5 \mu \mathrm{g} / \mathrm{ml}$ anti-CD3. (C) Cytokine secretion by EP2-expressing Th17 cells. EP2-overexpressing cells and mock-transduced Th17 cells were activated with an EP2 agonist in the presence of $5 \mu \mathrm{g} / \mathrm{ml}$ anti-CD3. Secretion of IFN- $\gamma$, GM-CSF, and IL-10 was analyzed by ELISA (mean \pm SEM; $n=5$ ). All $P$ values were calculated by an unpaired Student's $t$ test.

centrations of anti-CD3 antibodies. Th17 cells from ROR $\gamma \mathrm{t}^{-/}$ knockout mice were used as a specificity control (Supplemental Figure 4A). Strong $\mathrm{T}$ cell receptor stimulation diminished ROR $\gamma$ t binding to Ptger 2 both in the promoter region ( $5^{\prime}$ end) and at the $3^{\prime}$ end of the gene (Figure $8 \mathrm{C}$ ). Thus, $\mathrm{T}$ cell receptor signaling had a dose-dependent inhibitory influence on ROR $\gamma t$ binding to Ptger2. Importantly, even with higher concentrations of anti-CD3 antibodies, we observed significant binding of RORC to PTGER2 in Th17 cells from healthy subjects (Figure $8 \mathrm{D}$ ). To compare the influence of $\mathrm{T}$ cell receptor-signaling strength on RORC binding to PTGER2 in MS patients and healthy controls, Th17 cells were stimulated with the same concentration of anti-CD3 antibodies and analyzed by ChIP-PCR. RORC binding to PTGER2 was significantly more attenuated in Th17 cells from patients with MS as compared with Th17 cells from healthy control subjects (Figure 8D). Thus, the threshold of $\mathrm{T}$ cell receptor-mediated inhibition of the interaction between RORC and PTGER2 was lower in Th17 cells from MS patients. Finally, we found that EP2 expression was significantly higher in autoimmune pathogenic Th17 cells from patients with MS as compared with Th17 cells from healthy controls and that the upregulation of EP2 was dependent on the strength of $\mathrm{T}$ cell receptor stimulation (Figure $8 \mathrm{E}$ ). Taken together, RORC binding to PTGER2 and RORC-mediated suppression of EP2 were diminished, while EP2 expression was higher in Th17 cells from MS patients. As a consequence, EP2 expression promoted the upregulation of IFN- $\gamma$ and GM-CSF and induced a potentially pathogenic Th17 cell phenotype that was associated with a lower signaling threshold in CD4 T cells from MS patients.

\section{Discussion}

PGE2 plays different roles during inflammatory responses, showing either proinflammatory or immune-suppressive properties. Here, we show striking differences in expression of PGE2 receptors on different $T$ cell subsets with loss of the EP2 receptor on Th17 cells. Mechanistically, loss of EP2 expression was mediated by RORC, which directly silenced the EP2 receptor PTGER2 gene. The repression of EP2 expression on $\mathrm{CD}^{+}{ }^{+} \mathrm{T}$ cells mediated by RORC could in part be overcome by strong TCR signaling, which inhibited the binding of RORC to PTGER2. In Th17 cells from patients with MS, binding of RORC to PTGER2 was significantly reduced as compared with that in Th17 cells from healthy individuals when cells were stimulated with the same $\mathrm{T}$ cell receptor-signaling strength, suggesting that the lower $\mathrm{T}$ cell-signaling threshold observed in human autoimmune disease was responsible for the disturbed interaction between RORC and PTGER2. Overexpression of EP2 in Th17 cells from healthy individuals induced a potentially pathogenic Th17 cell phenotype with increased expression of IFNG, STAT4, TBX21, IL22, CSF2, and RUNX3 and decreases in IL10 and AHR genes. Thus, prostaglandins may mediate induction of pathogenic $\mathrm{CD}^{+}$cells in patients with autoimmune disease.

Overexpression of EP2 in Th17 cells induces a pathogenic phenotype similar to that previously described in human Th17 cells during fungal infection (32) and in mice with EAE (30). These pathogenic Th17 cells produce IL-17, IFN- $\gamma$, and GM-CSF, but no IL-10 (30). In mice, T-bet ${ }^{-/}$Th17 cells lose their ability to induce autoimmunity, further suggesting a key role for T-bet in Th17 cells in mediating a pathogenic CD4 cell phenotype (26). In this regard, our 
A
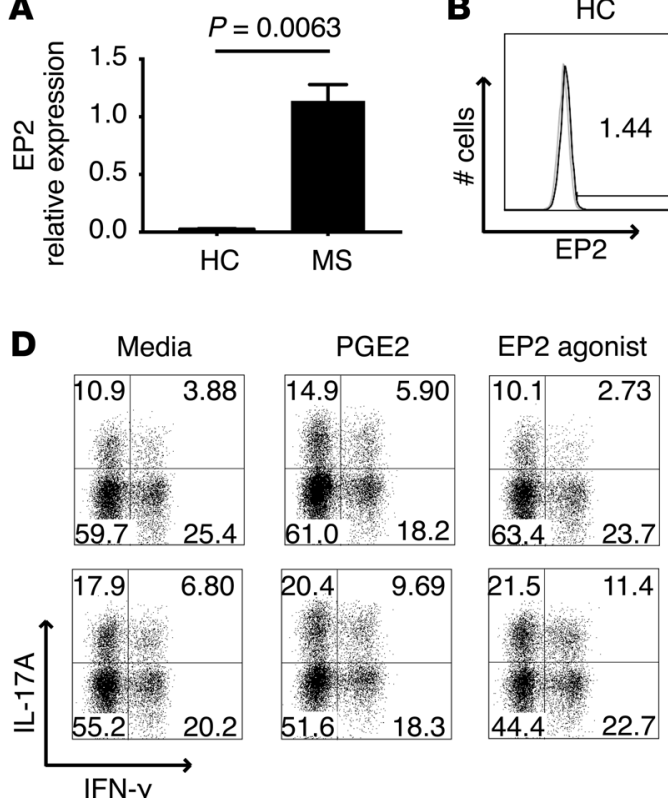

IFN-Y
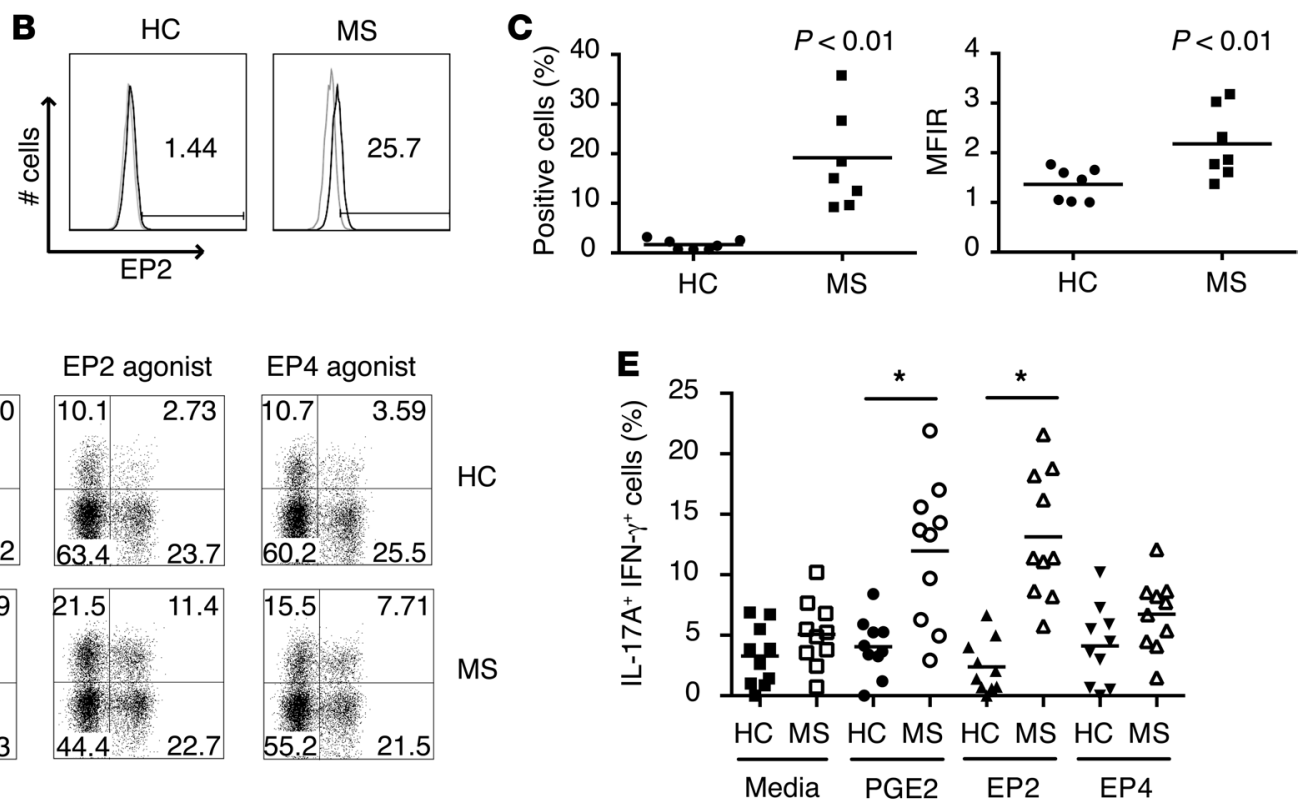

Figure 6

EP2 expression is increased in Th17 cells from MS patients. (A) EP2 expression in Th17 cells from healthy controls (HC) and Th17 cells from MS patients were compared using RT-PCR (mean \pm SEM; $n=20$ ). Representative example $(\mathbf{B})$ and cumulative results $(\mathbf{C})$ of flow cytometric analysis of EP2 in Th17 cells from MS patients and healthy controls. $n=7$. Percentage of positive cells and mean fluorescence intensity ratio $(\mathrm{MFIR})=\mathrm{MFI}$ (EP2) - MFI (isotype) are shown. Representative example (D) and cumulative results (E) of flow cytometric analysis of IL-17A and IFN- $\gamma$ in CD4+ T cells from MS patients and healthy controls. CD45RO+ memory CD4+ $\mathrm{T}$ cells from healthy controls and MS patients were cultured for 4 days with IL-23. Where indicated, cells were cultured in the presence of PGE2, an EP2 agonist (butaprost), or an EP4 agonist (misoprostol). Percentage of IL-17A+IFN- $\gamma^{+}$Th17 cells in MS patients and healthy controls are shown. ${ }^{*} P<0.01 . n=10$.

transcriptional analysis of EP2-overexpressing Th17 cells showed an upregulation of genes encoding for IFN- $\gamma$, T-bet, RUNX3, and STAT4. The transcription factors T-bet and RUNX3 cooperate to differentiate Th1 cells and induce IFN- $\gamma$ production $(33,34)$. Furthermore, T-bet and STAT 4 are critical for IFN- $\gamma$ production in Th1 cells (35). The changes we observed in gene transcription that resulted in increased expression of T-bet, RUNX3, STAT4, and IFN- $\gamma$ in EP2-overexpressing Th17 cells, without loss of RORC and IL-17A, indicate that these cells shifted to IL- $17^{+}$IFN- $\gamma^{+}$double-producing cells. In addition to IFN- $\gamma$, we found that EP2-overexpressing Th17 cells expressed increased levels of GM-CSF and IL-22 but decreased levels of IL-10 and of the transcription factor AHR. Taken together, the EP2 overexpression in Th17 cells induces a gene expression profile that is similar to the gene signature found in autoimmune, pathogenic Th17 cells $(26,36)$.

Interestingly, EP2 is temporarily upregulated during early Th17 cell differentiation. While EP2 and EP4 signaling often acts synergistically, a number of different receptor-specific effects have been described. Activation of EP2 and EP4 induces PI3K signaling and enhances intracellular cAMP concentrations (11, 37). Suppression of IL-10 and IFN- $\gamma$ production in Th17 cells is predominantly mediated through EP4 signaling (13). Furthermore, EP4 signaling is responsible for PGE2-induced immune inflammation and disease progression in $\operatorname{EAE}(11,14)$. Our findings may, in part, explain the different immunological effects of PGE2 on distinct $\mathrm{CD} 4^{+} \mathrm{T}$ cell subsets, as we show that Th17 cells are activated by PGE2 through the EP4 receptor alone, while Th1, Th2, Th9, and Tregs are activated through EP2 and EP4 recep- tors. Whether genetic variation in the EP4 receptor region (4) influences susceptibility to autoimmune disease through interactions with the EP2 receptor is unknown.

PGE2 has paradoxical effects on Th17 cells, inhibiting the induction of Th17 cells from naive $\mathrm{CD}^{+} \mathrm{T}$ cells (15), but promoting expansion of mature Th17 cells (11-13). The suppression of IL-17 production during Th17 cell differentiation is mediated by inhibition of the transcription factor IRF4 and can be reversed by EP2 antagonists, but not by EP4 antagonists (15). The paradoxical effect of PGE2 on IL-17 production could be explained by differences in EP2 expression during Th17 cell induction and expansion. While activation of naive $\mathrm{CD} 4{ }^{+} \mathrm{T}$ cells induced a temporary increase in EP2 expression during Th17 cell differentiation, EP2 was substantially suppressed in mature Th17 cells. This is consistent with the observation that EP4, and not EP2, is predominantly responsible for Th17 cell expansion and increased IL-17 production (11). Loss of EP2 on mature Th17 cells could thus explain the paradoxical effect of PGE2 on Th17 induction from naive $\mathrm{CD} 4^{+} \mathrm{T}$ cells and on the expansion of mature Th17 cells.

PGE2-mediated Th17 cell expansion induces disease progression in EAE. In patients with MS, PGE2 levels are elevated in the serum and in the cerebrospinal fluid $(20,21)$. However, the role of PGE2 in the pathogenesis of MS and other autoimmune diseases remains unknown. PGE2 has been shown to promote Th17 cell expansion by upregulation of IL-23 and IL-1 $\beta$ receptor (13). Our results showed a significant increase in the frequency of IL-17A $\mathrm{A}^{+} \mathrm{IFN}-\gamma^{+}$ cells mediated through EP2 signaling in Th17 cells from patients with MS. In marked contrast, we did not observe expansion of 
A

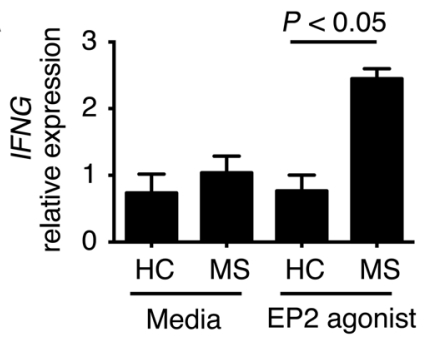

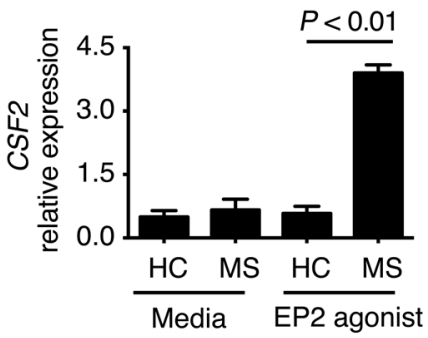

B

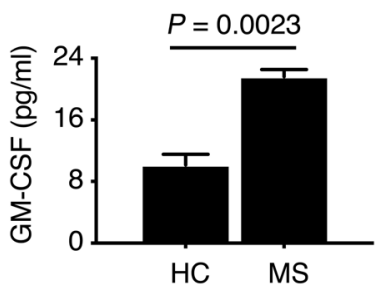

Figure 7

EP2 activation drives cytokine production in Th17 cells from MS patients. (A) RT-PCR analysis of IFNG and CSF2 mRNA expression in Th17 cells from MS patients and healthy controls (mean \pm SEM; $n=5$ ). Th17 cells were differentiated for 4 days from naive CD4 ${ }^{+} \mathrm{T}$ cells. Where indicated, cells were cultured in the presence of the EP2 agonist butaprost. (B) Secretion of GM-CSF by Th17 cells from MS patients and healthy controls was analyzed by ELISA; mean \pm SEM. $n=5$. All $P$ values were calculated by an unpaired Student's $t$ test.

IL-17A IFN- $\gamma^{+}$cells by EP2 agonists in Th17 cells from healthy individuals, as EP2 expression was silenced in these cells. Nonphysiological EP2 signaling in Th17 cells therefore favored the expansion of IFN- $\gamma^{+} \mathrm{GM}-\mathrm{CSF}^{+}$Th17 cells (Figure 9). We know from previous studies that all IL-17A IFN- $\gamma^{+}$double-producing $\mathrm{CD}^{+}{ }^{+} \mathrm{T}$ cells are derived from Th17 cells (30). This excludes the possibility that Th1 cells are responsible for the increase in IL- $17 \mathrm{~A}^{+} \mathrm{IFN}-\gamma^{+}$double-producing cells we observed in MS patients.

The level of EP2 expression in $\mathrm{CD}^{+} \mathrm{T}$ cells depends on the strength of the TCR stimulation (Figure 4A). We have shown that RORCmediated PTGER2 silencing can be partly overcome by a strong TCR signal (Figure 4A). This is consistent with previous reports showing that strong TCR stimulation leads to transient downregulation of
IL-17 in Th17 cells mediated by decreased expression of ROR $\gamma t$ (32). RORC expression remained stable after strong TCR stimulation of RORC-overexpressing $\mathrm{CD}^{+}{ }^{+} \mathrm{T}$ cells (Figure 4B). The signaling threshold of $\mathrm{CD}^{+} \mathrm{T}$ cells is genetically decreased in autoimmune disease (27). Thus, it is likely that the enhanced TCR signaling in T cells from patients with MS and other autoimmune diseases drives the increased EP2 expression. Reduced PTGER2 silencing may biologically reflect the consequences of an increased TCR signal strength.

Our findings reveal EP2 to be a potential drug target in autoimmune disease. The application of EP2 antagonists could help to reduce the frequency of pathogenic IL-17A IFN- $\gamma^{+}$Th17 cells in patients with MS. Various prostanoid receptor antagonists have been developed in recent years, including a highly selective and potent EP2
A

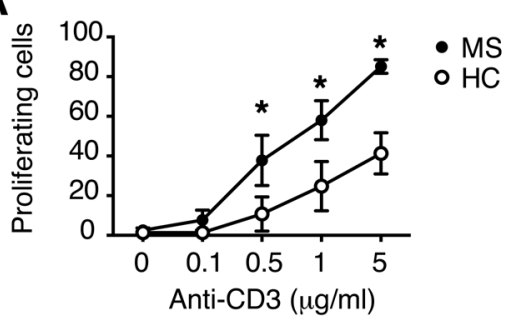

C

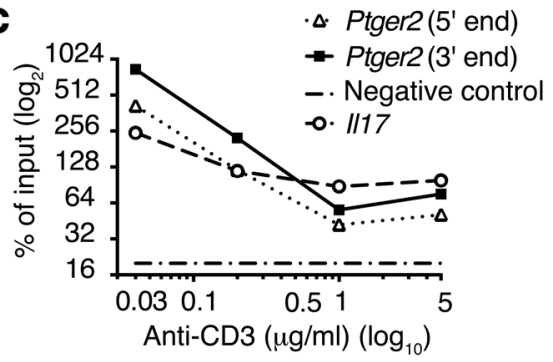

B

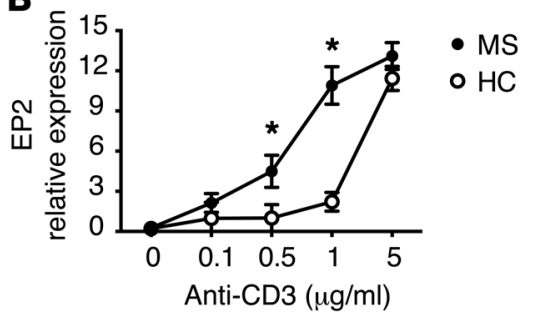

D

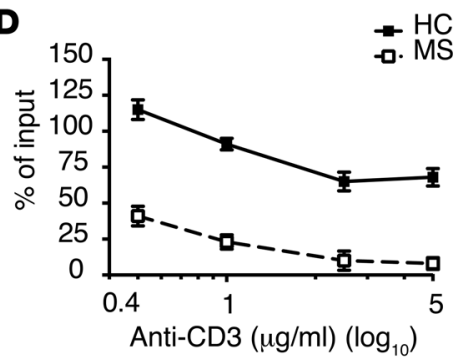

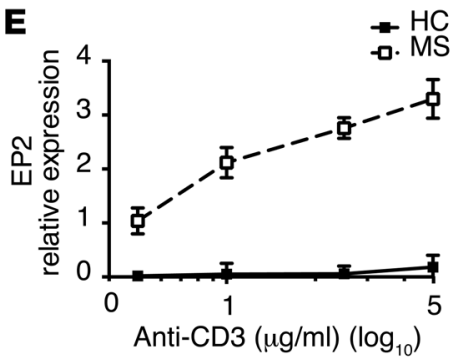

Figure 8

Influence of TCR signaling strength on EP2 expression and RORC binding to PTGER2 in Th17 cells. (A) Proliferative response of CD4+ T cells from healthy controls and MS patients. Cells were cultured for 3 days in the presence of different anti-CD3 antibody concentrations, and proliferation was measured by CFSE dilution using flow cytometry. ${ }^{*} P<0.05$. (B) CD4+ $\mathrm{T}$ cells from MS patients upregulated EP2 at lower anti-CD3 concentrations as compared with those in healthy controls. ${ }^{*} P<0.05$. (C) Murine Th17 cells were stimulated with different concentrations of anti-CD3 antibodies, and binding of ROR $\gamma$ t to the promoter region ( $5^{\prime}$ end) and the $3^{\prime}$ end of Ptger2 was analyzed by quantitative real-time PCR of ChIP-PCR. Dashed line indicates background using cells from ROR $\gamma \mathrm{t}^{-1-}$ mice. Binding of ROR $\gamma \mathrm{t}$ to the $/ 17$ locus was used as a control. (D) ChIP-PCR analysis of RORC binding to the PTGER2 promoter region ( $5^{\prime}$ end) in Th17 cells from MS patients and healthy controls. Th17 cells were stimulated with different concentrations of anti-CD3 antibodies (mean \pm SEM; $n=3$ ). (E) TCR signaling-dependent EP2 expression in Th17 cells from MS patients and healthy controls was analyzed by RT-PCR (mean \pm SEM; $n=3$ ). 

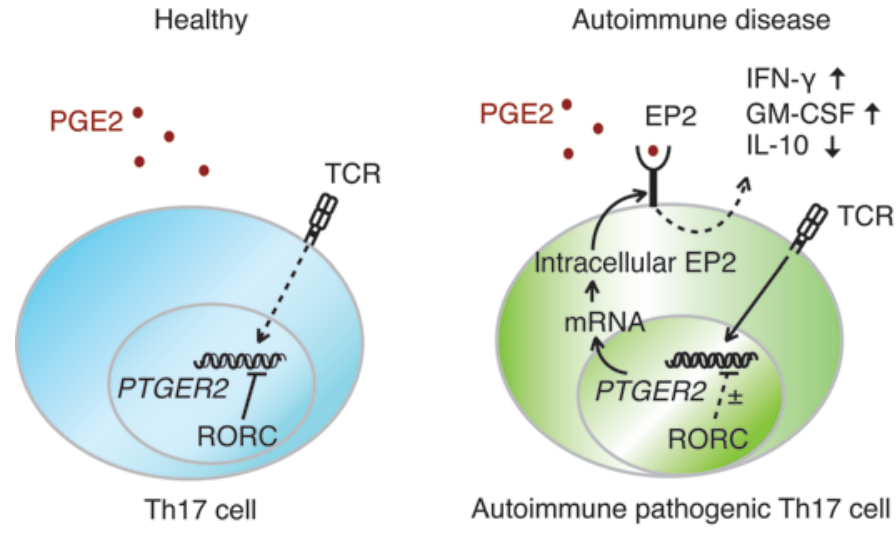

Autoimmune pathogenic Th17 cell
Th17 gene signature

\begin{tabular}{lc|c}
\cline { 2 - 3 } Gene & $\begin{array}{c}\text { EP2- } \\
\text { induced }\end{array}$ & Pathogenic \\
IFNG & $\uparrow$ & $\uparrow$ \\
CSF2 & $\uparrow$ & $\uparrow$ \\
TBX21 & $\uparrow$ & $\uparrow$ \\
STAT4 & $\uparrow$ & $\uparrow$ \\
IL22 & $\uparrow$ & $\uparrow$ \\
AHR & $\downarrow$ & $\downarrow$ \\
IL10 & $\downarrow$ & $\downarrow$
\end{tabular}

\section{Figure 9}

Model for PGE2 effects on Th17 cells in healthy individuals and autoimmune disease. TCR-induced EP2 upregulation is inhibited by RORC in Th17 cells from healthy individuals. In Th17 cells from patients with autoimmune disease, RORC-mediated PTGER2 silencing is diminished and EP2 is expressed. EP2 signaling in pathogenic Th17 cells promotes the induction of IL-17A+IFN- $\gamma^{+}$cells and induces a potentially pathogenic Th17 cell phenotype (26).

receptor antagonist that is currently under clinical investigation to assess safety and tolerability in humans (38). While the specific role of IFN- $\gamma^{+} \mathrm{GM}-\mathrm{CSF}^{+}$Th17 cells in MS pathophysiology is unknown, recent findings provide evidence that these cells are implicated in the pathogenesis of autoimmune disease. GM-CSF production in helper T cells is driven by ROR $\gamma t$ (39), and the encephalitogenicity of Th17 cells in EAE is dependent on their production of GM-CSF (40). High frequencies of IFN- $\gamma^{+} \mathrm{GM}-\mathrm{CSF}^{+}$Th17 cells have been found during the acute phase of EAE (30). Furthermore, IL-17+IFN- $\gamma^{+}$ cells have been found in the CNS of MS patients (41). Th17 cells from MS patients are more likely to develop into IL- $17^{+} \mathrm{IFN}-\gamma^{+}$cells than are Th17 cells from healthy individuals (41). Thus, reduction of IL- $17^{+}$IFN- $\gamma^{+}$Th17 cell numbers is a potential strategy for the treatment of autoimmune disease.

In summary, we describe a specific mechanism by which RORC downregulates EP2 in normal Th17 cells by directly silencing PTGER2 and prevents induction of potentially pathogenic Th17 cells. The striking differences in EP2 expression between distinct CD4 ${ }^{+}$ $\mathrm{T}$ cell subsets provide an explanation for the opposing effects of PGE2 on Th1 and Th17 cells. Furthermore, the short-term upregulation of EP2 during early Th17 cell differentiation from naive $\mathrm{CD}^{+} \mathrm{T}$ cells likely explains the paradoxical effects of PGE2 on Th17 cells during induction and expansion. Finally, binding of RORC to PTGER2 and downregulation of EP2 are disturbed in Th17 cells from MS patients, leading to increased frequencies of pathogenic IFN- $\gamma^{+} \mathrm{GM}-\mathrm{CSF}^{+}$Th17 cells. These findings identify EP2 as a potential target for the treatment of autoimmune diseases.

\section{Methods}

Study subjects. Peripheral blood was drawn from healthy individuals and patients with MS. All patients had RRMS with Kurtzke Expanded Disability Status Scale scores between 0 and 2.5. The patients were $43.5 \pm 12.3$ years of age. All patients were untreated or had not received treatment for at least 12 months. Healthy controls were age and sex matched with the MS patients and had no history of autoimmune disease or malignancies and no acute or chronic infections.

Human Tcell isolation and cell culture. Primary human lymphocytes were isolated from peripheral blood of healthy subjects or untreated patients with RRMS by Ficoll gradient centrifugation (GE Healthcare). Untouched CD $4^{+}$
$\mathrm{T}$ cells were isolated from PBMCs by negative selection via the $\mathrm{CD} 4^{+} \mathrm{T}$ cell isolation kit II (Miltenyi Biotec). Naive (CD45RA $\left.{ }^{+} \mathrm{CD} 45 \mathrm{RO}^{-} \mathrm{CD} 25^{-} \mathrm{CD} 127^{+}\right)$ and memory (CD45RA-CD45RO $\left.{ }^{+} \mathrm{CD} 25^{-} \mathrm{CD} 127^{+}\right) \mathrm{CD}^{+} \mathrm{T}$ cells were then sorted by high-speed flow cytometry with a FACSAria (BD Biosciences) to a purity of greater $98 \%$ as verified by post-sort analysis. Dead cells were excluded by propidium iodide (BD Biosciences). Cells were cultured in 96-well, round-bottom plates (Costar) at $5 \times 10^{4}$ cells per well in RPMI 1640 medium, 10\% (v/v) FCS (Life Technologies) and stimulated with platebound anti-CD3 $(5 \mu \mathrm{g} / \mathrm{ml})$ and soluble anti-CD28 $(1 \mu \mathrm{g} / \mathrm{ml})$ Abs.

Isolation and purification of Th17 cells. Ex vivo-isolated CD4 $4^{+} \mathrm{T}$ cells were purified from the peripheral blood of healthy donors and MS patients using the magnetic cell-sorting (MACS) technique. $\mathrm{CD}^{+} \mathrm{T}$ cells were activated with PMA-ionomycin for 2 hours, and IL-17 expression on the cell surface was stained with anti-IL17A antibodies without prior permeabilization of the cells $(42,43)$. IL-17+ cells and IL-17- cells were then sorted using FACSAria. RORC and IL17A mRNA expression was analyzed in both subgroups.

Differentiation of T cell subsets. For differentiation of human Th17 cells, naive $\mathrm{CD} 4^{+} \mathrm{T}$ cells were cultured for 4 days with recombinant human (rh) TGF- $\beta$ (5 ng/ml), IL-1 $(12.5 \mathrm{ng} / \mathrm{ml})$, IL-6 $(25 \mathrm{ng} / \mathrm{ml})$, IL-21 $(25 \mathrm{ng} / \mathrm{ml})$, and IL-23 $(25 \mathrm{ng} / \mathrm{ml})$. rhIL-2 was obtained from the AIDS Research and Reference Reagent Program, Division of AIDS, National Institute of Allergy and Infectious Diseases (NIAID), NIH, and was used for restimulation experiments at $20 \mathrm{U} / \mathrm{ml}$. Cells were cultured for the periods of time indicated below. For differentiation of $\mathrm{CD}^{+} \mathrm{T}$ cell subsets, the following cytokines or $\mathrm{mAbs}$ were used: Th0 cells were cultured with IL-2 $(20 \mathrm{U} / \mathrm{ml})$; Th1 cells were cultured with rhIL-12 $(10 \mathrm{ng} / \mathrm{ml})$ and anti-IL-4 $\mathrm{mAb}(10 \mu \mathrm{g} / \mathrm{ml})$; Th2 cells were cultured with rhIL-4 $(10 \mathrm{ng} / \mathrm{ml})$ and anti-IFN- $\gamma \mathrm{mAb}(10 \mu \mathrm{g} / \mathrm{ml})$; and Th9 cells were cultured with rhIL-4 (10 ng/ml), rhTGF- $\beta(5 \mathrm{ng} / \mathrm{ml})$, and anti-IFN- $\gamma$ $\mathrm{mAbs}(10 \mu \mathrm{g} / \mathrm{ml})$. All cytokines and antibodies were obtained from R\&D Systems. CD $4{ }^{+} \mathrm{CD} 25^{\text {hi }} \mathrm{CD} 127^{\text {lo }}$ Tregs were sorted by FACSAria. CD45RA ${ }^{-}$ $\mathrm{CD}_{5} 5 \mathrm{RO}^{+}$memory $\mathrm{CD}^{+} \mathrm{T}$ cells were cultured with $5 \mu \mathrm{g} / \mathrm{ml}$ anti-CD 3 and $1 \mu \mathrm{g} / \mathrm{ml}$ anti-CD28 in the presence of rhIL-1 $\beta$, rhIL-6, rhIL-21, rhIL23, and rhTGF- $\beta$ for 4 days and then expanded for an additional 5 days with IL-23. Where indicated, cells were incubated with $0.1 \mu \mathrm{M}$ PGE2, $0.1 \mu \mathrm{M}$ butaprost, or $0.1 \mu \mathrm{M}$ misoprostol (Cayman Chemical).

Antibodies, recombinant cytokines, and reagents. The following $\mathrm{mAbs}$ were used: anti-CD4 (RPA-T4), anti-CD45RO (UCHL1), anti-CD45RA (HI100), anti-CD25 (M-A251), anti-CD127 (hIL-7R-M21), anti-CCR6 (11A9) (all from BD Biosciences) - for surface staining; anti-IL-17A (eBio64DEC17; 
eBioscience) and anti-IFN- $\gamma$ (B27; BD Biosciences) - for intracellular staining; and anti-CD3 (UCHT1) and anti-CD28 (28.2) from BD Biosciences - for $\mathrm{T}$ cell stimulation. Anti-EP2 and anti-EP4 antibodies were purchased from Cayman Chemical.

EP2 overexpression in Th17 cells. Naive human CD45RA ${ }^{+} \mathrm{CD} 45 \mathrm{RO}^{-} \mathrm{CD} 4^{+}$ $\mathrm{T}$ cells were cultured for 2 days with $10 \mu \mathrm{g} / \mathrm{ml}$ anti-CD3 and $1 \mu \mathrm{g} / \mathrm{ml}$ anti-CD28 antibodies in the presence of rhIL-1 $\beta$, rhIL-6, rhIL-21, rhIL23, and rhTGF- $\beta$. For gene overexpression, an EP2 gene expression construct (OriGene Technologies) or a mock control construct was delivered into Th17 cells by electroporation nucleofection (Amaxa) according to the manufacturer's instructions. After gene transfer, the cells were cultured for an additional 2 days under Th17-skewing conditions.

Flow cytometry. Cells were analyzed by flow cytometry after a culture period of 7 to 8 days, unless otherwise specified. For surface staining, cells were stained with the respective antibodies for 20 minutes in PBS containing $0.5 \% \mathrm{FCS}$ and $2 \mathrm{mM}$ EDTA before analysis. For intracellular staining, cells were stimulated for 4 to 5 hours with PMA $(50 \mathrm{ng} / \mathrm{ml})$ and ionomycin $(250 \mathrm{ng} / \mathrm{ml}$; both from Sigma-Aldrich) in the presence of GolgiPlug (BD Biosciences), fixed and made permeable (Fix/Perm; eBioscience) according to the manufacturer's instructions, and stained with the respective antibodies for intracellular cytokine detection for 30 to 45 minutes. Prior to fixation, cells were stained with the LIVE/DEAD cell kit (Invitrogen) to exclude dead cells. Data were acquired on an LSR II (BD Biosciences) and analyzed with FlowJo software (Tree Star Inc.).

ELISAs. CD4 ${ }^{+} \mathrm{T}$ cells were cultured with anti-CD3 $(10 \mu \mathrm{g} / \mathrm{ml})$ and antiCD28 $(1 \mu \mathrm{g} / \mathrm{ml})$ antibodies in the presence of IL-1 $\beta$, IL-6, IL-21, IL23, and TGF- $\beta$ for 4 days. Supernatants were collected, and IL-17, IFN- $\gamma$, GM-CSF, and IL-10 measurement was performed according to the manufacturer's recommendations (BD Biosciences). rhIFN, rhGM-CSF, rhIL-17, and rhIL10 were purchased from Chiron.

Real-time PCR. Cells for RNA isolation were harvested after 4 days of cell culture, unless otherwise specified, and RNA was isolated using the Absolutely RNA 96 Microprep Kit (Agilent Technologies) or the RNeasy micro kit (QIAGEN) and converted to cDNA via RT by random hexamers and Multiscribe RT (TaqMan Gold RT-PCR kit; Applied Biosystems). All primers were purchased from Applied Biosystems. All reactions were performed on a StepOnePlus Real-Time PCR System (Applied Biosystems). The values are represented as the difference in $\mathrm{Ct}$ values normalized to $\beta$-microglobulin for each sample using the following formula: relative RNA expression $=\left(2^{-\mathrm{dCt}}\right) \times 10^{3}$.

Mice and murine Th17 cell differentiation. C57BL/ 6 WT mice were housed and maintained in a conventional pathogen-free facility at the Harvard Institute of Medicine.

$\mathrm{CD}^{+} \mathrm{T}$ cells were purified from spleen and lymph nodes from C57BL/6 WT mice with anti-CD4 microbeads (Miltenyi Biotec), then were further sorted as naive $\mathrm{CD} 4{ }^{+} \mathrm{CD} 62 \mathrm{~L}^{\text {hi }} \mathrm{CD} 44^{\text {lo }} \mathrm{T}$ cells. Sorted cells were activated with plate-bound anti-CD3 (2 $\mu \mathrm{g} / \mathrm{ml}$; 1452C11; Bio X Cell) and anti-CD28 $(2 \mu \mathrm{g} / \mathrm{ml}$; PV1; Bio X Cell) in the presence of cytokines (recombinant mouse IL-23 from R\&D Systems; all other cytokines were from Miltenyi Biotec). For Th17 differentiation, the following reagents were used: $2 \mathrm{ng} / \mathrm{ml}$ recombinant mouse TGF- $\beta$ (Miltenyi Biotec), $25 \mathrm{ng} / \mathrm{ml}$ recombinant mouse IL-6 (Miltenyi Biotec), $20 \mathrm{ng} / \mathrm{ml}$ recombinant mouse IL-23 (R\&D Systems), and $20 \mathrm{ng} / \mathrm{ml}$ recombinant mouse IL-1 $\beta$ (Miltenyi Biotec). Cells were cultured for 4 days and collected for RNA, intracellular cytokine staining, and flow cytometry.

ChIP-PCR and sequencing. ChIP was performed as described previously (44). Briefly, Th17 cells from Rorc $^{+/+} \mathrm{C} 57 \mathrm{BL} / 6$ WT mice and CD4-Cre Rord $^{\text {fl/l/ }}$ mice (45) were lysed and sonicated to solubilize and shear cross-linked DNA. Purified DNA was blunted and amplified using a 2-stage PCR protocol.

ChIP-sequencing (ChIP-seq) was performed as described previously (45). reads were aligned with the NCBI Build 37 (UCSC mm9) of the mouse genome using Bowtie9. Enriched binding regions (peaks) were detected using MACS10 and QuEST, with a $P$ value cutoff of $10^{-8}$. Unspecific binding to ROR $\gamma t$ was controlled by isotype control immunoglobulin (IgG) and by an anti-ROR $\gamma t$ antibody in a ROR $\gamma t$-deficient cell population.

The ChIP-seq data are available in the NCBI's Gene Expression Omnibus (GEO) database (GEO GSE56020; http://www.ncbi.nlm.nih.gov/gds).

shRNA-mediated gene silencing. Lentiviral particles expressing siRNAs were obtained from Sigma-Aldrich. Lentiviral transduction of human T cells was carried out as described before (17). In brief, $5 \times 10^{4}$ human naive $\mathrm{CD} 4{ }^{+} \mathrm{T}$ cells per well were stimulated for 24 hours prior to infection with anti-CD3 and anti-CD28. Cells were then transduced with viral particles containing a vector expressing RORC-specific siRNA or unspecific siRNA. Cells were transduced using an MOI of 5 and centrifugation at $800 \mathrm{~g}$ for 30 minutes at room temperature in the presence of $3 \mu \mathrm{g} / \mathrm{ml}$ polybrene (Millipore). The efficiency of RORC knock down was verified by Western blotting. The specific RNAi Consortium clone used for RORC knock down was TRCN0000033654. Cells were analyzed for EP2 expression 48 hours after transduction with siRNA.

Luciferase activity assay. Naive human $\mathrm{CD}^{+}{ }^{+} \mathrm{CD} 45 \mathrm{RA}^{+} \mathrm{CD} 45 \mathrm{RO}-\mathrm{T}^{-} \mathrm{T}$ cells were transfected by electroporation with various concentrations of a RORC expression plasmid and with a luciferase reporter construct (SwitchGear Genomics) containing the first 104 base pairs of the PTGER2 promoter region. Luciferase activity was analyzed 48 hours after transfection and 24 hours after activation with PMA and ionomycin using a dual luciferase assay kit (Promega).

Statistics. Statistical analysis was performed using GraphPad Prism (GraphPad Software). Data were analyzed by 1-way ANOVA using Tukey's post-hoc test in multiple groups and by a 2 -tailed unpaired Student's $t$ test in cases in which 2 groups were compared. Data are presented as the mean \pm SEM, and $P<0.05$ was considered statistically significant.

Study approval. The study was conducted in compliance with the Declaration of Helsinki. Before study initiation, approval was obtained from the ethics committee of Yale-New Haven Hospital (New Haven, Connecticut, USA). Written informed consent was obtained from all patients and healthy donors. All animal experiments were conducted in accordance with the guidelines outlined by the Harvard Medical Area Standing Committee on Animals at Harvard Medical School. Approval of the Harvard Medical Area Standing Committee on Animals was obtained for all animal experiments.

\section{Acknowledgments}

This work was supported by the Deutsche Forschungsgemeinschaft (KO 4034/1-1, to D.M. Kofler) and by NIH grants P01 AI045757, U19 AI046130, U19 AI070352, and P01 AI039671 (to D.A. Hafler). This work was also supported by a Jacob Javits Merit Award (NS2427, to D.A. Hafler) from the National Institute of Neurological Disorders and Stroke, by a Collaborative Multiple Sclerosis Research Center Award from the National Multiple Sclerosis Society and the Nancy Taylor Foundation for Chronic Diseases Inc. V.K. Kuchroo is supported by NIH grants R01NS030843, P01NS076410, and P01AI039671, and S. Xiao is supported by NIH grant K01DK090105 and by the National Multiple Sclerosis Society.

Received for publication August 30, 2013, and accepted in revised form March 20, 2014.

Address correspondence to: David M. Kofler or David A. Hafler, Yale School of Medicine, 15 York Street, PO Box 208018, New Haven, Connecticut 06520-8018, USA. Phone: 203.785.5947; Fax: 203.785.2238; E-mail: david.kofler@yale.edu (D.M Kofler), david. hafler@yale.edu (D.A. Hafler). 
1. Kalinski P. Regulation of immune responses by prostaglandin E2. J Immunol. 2012;188(1):21-28.

2. Sreeramkumar V, Fresno M, Cuesta N. Prostaglandin E2 and T cells: friends or foes? Immunol Cell Biol. 2012;90(6):579-586.

3. Sakata D, Yao C, Narumiya S. Prostaglandin E2, an immunoactivator. J Pharmacol Sci. 2010;112(1):1-5.

4. De Jager PL, et al. Meta-analysis of genome scans and replication identify CD6, IRF8, and TNFRSF1A as new multiple sclerosis susceptibility loci. Nat Genet. 2009;41(7):776-782.

5. International Multiple Sclerosis Genetics Consortium, et al. Genetic risk and a primary role for cell-mediated immune mechanisms in multiple sclerosis. Nature. 2011:476(7359):214-219.

6. Libioulle C, et al. Novel Crohn disease locus identified by genome-wide association maps to a gene desert on 5 p13.1 and modulates expression of PTGER4. PLoS Genet. 2007;3(4):e58.

7. McGovern DP, et al. Genome-wide association identifies multiple ulcerative colitis susceptibility loci. Nat Genet. 2010;42(4):332-337.

8. Betz M, Fox BS. Prostaglandin E2 inhibits production of Th1 lymphokines but not of Th2 lymphokines. J Immunol. 1991;146(1):108-113.

9. Harris SG, Padilla J, Koumas L, Ray D, Phipps RP. Prostaglandins as modulators of immunity. Trends Immunol. 2002;23(3):144-150.

10. Gold KN, Weyand CM, Goronzy JJ. Modulation of helper T cell function by prostaglandins. Arthritis Rheum. 1994:37(6):925-933.

11. Yao C, et al. Prostaglandin E2-EP4 signaling promotes immune inflammation through Th1 cell differentiation and Th17 cell expansion. Nat Med. 2009;15(6):633-640.

12. Napolitani G, Acosta-Rodriguez EV, Lanzavecchia A, Sallusto F. Prostaglandin E2 enhances Th17 responses via modulation of IL-17 and IFN- $\gamma$ production by memory $\mathrm{CD}^{+} \mathrm{T}$ cells. Eur J Immunol. 2009;39(5):1301-1312.

13. Boniface K, et al. Prostaglandin E2 regulates Th17 cell differentiation and function through cyclic $\mathrm{AMP}$ and EP2/EP4 receptor signaling. J Exp Med. 2009;206(3):535-548.

14. Esaki Y, et al. Dual roles of PGE2-EP4 signaling in mouse experimental autoimmune encephalomyelitis. Proc Natl Acad SciUS A. 2010;107(27):12233-12238.

15. Valdez PA, Vithayathil PJ, Janelsins BM, Shaffer AL, Williamson PR, Datta SK. Prostaglandin E2 suppresses antifungal immunity by inhibiting interferon regulatory factor 4 function and interleukin-17 expression in T cells. Immunity. 2012; 36(4):668-679.
16. Sugimoto Y, Narumiya S. Prostaglandin E receptors. J Biol Chem. 2007;282(16):11613-11617.

17. Astier AL, Beriou G, Eisenhaure TM, Anderton SM, Hafler DA, Hacohen N. RNA interference screen in primary human T cells reveals FLT3 as a modulator of IL-10 levels. J Immunol. 2010;184(2):685-693.

18. Traugott U, Reinherz EL, Raine CS. Multiple sclerosis: distribution of $\mathrm{T}$ cell subsets within active chronic lesions. Science. 1983;219(4582):308-310.

19. Kornek B, et al. Multiple sclerosis and chronic autoimmune encephalomyelitis: a comparative quantitative study of axonal injury in active, inactive, and remyelinated lesions. Am J Pathol. 2000;157(1):267-276.

20. Mattsson N, et al. Elevated cerebrospinal fluid levels of prostaglandin E2 and 15-(S)-hydroxyeicosatetraenoic acid in multiple sclerosis. J Intern Med. 2009;265(4):459-464.

21. Pruss H, et al. Proresolution lipid mediators in multiple sclerosis - differential, disease severitydependent synthesis - a clinical pilot trial. PLoS One. 2013;8(2):e55859.

22. Steinman L. A brief history of $\mathrm{T}(\mathrm{H}) 17$, the first major revision in the $\mathrm{T}(\mathrm{H}) 1 / \mathrm{T}(\mathrm{H}) 2$ hypothesis of T cell-mediated tissue damage. Nat Med. 2007; 13(2):139-145

23. Steinman L. A rush to judgment on Th17. J Exp Med. 2008;205(7):1517-1522.

24. Tzartos JS, et al. Interleukin-17 production in central nervous system-infiltrating $T$ cells and glial cells is associated with active disease in multiple sclerosis. Am J Pathol. 2008;172(1):146-155.

25. Moldovan IR, et al. Interferon $\gamma$ responses to myelin peptides in multiple sclerosis correlate with a new clinical measure of disease progression. J Neuroimmunol. 2003;141(1-2):132-140.

26. Lee $Y$, et al. Induction and molecular signature of pathogenic TH17 cells. Nat Immunol. 2012;13(10):991-999.

27. Maier LM, Anderson DE, De Jager PL, Wicker LS, Hafler DA. Allelic variant in CTLA4 alters T cell phosphorylation patterns. Proc Natl Acad Sci U S A. 2007;104(47):18607-18612

28. Korn T, Bettelli E, Oukka M, Kuchroo VK. IL-17 and Th17 cells. Annu Rev Immunol. 2009;27:485-517.

29. Kickler K, et al. Prostaglandin E2 affects T cell responses through modulation of CD46 expression. J Immunol. 2012;188(11):5303-5310.

30. Hirota K, et al. Fate mapping of IL-17-producing $\mathrm{T}$ cells in inflammatory responses. Nat Immunol. 2011;12(3):255-263.

31. Hafler DA, Fox DA, Manning ME, Schlossman SF, Reinherz EL, Weiner HL. In vivo activated T lymphocytes in the peripheral blood and cerebrospinal fluid of patients with multiple sclerosis. $N$ Engl J Med. 1985;312(22):1405-1411.

32. Zielinski CE, et al. Pathogen-induced human TH17 cells produce IFN- $\gamma$ or IL-10 and are regulated by IL-1 $\beta$. Nature. 2012;484(7395):514-518.

33. Djuretic IM, Levanon D, Negreanu V, Groner Y, Rao A, Ansel KM. Transcription factors T-bet and Runx3 cooperate to activate Ifng and silence Il 4 in T helper type 1 cells. Nat Immunol. 2007;8(2):145-153.

34. Kohu K, et al. The Runx3 transcription factor augments Th1 and down-modulates Th2 phenotypes by interacting with and attenuating GATA3. Immunol. 2009;183(12):7817-7824.

35. Zhu J, et al. The transcription factor T-bet is induced by multiple pathways and prevents an endogenous Th2 cell program during Th1 cell responses. Immunity. 2012;37(4):660-673.

36. Peters A, Lee Y, Kuchroo VK. The many faces of Th17 cells. Curr Opin Immunol. 2011;23(6):702-706.

37. Fujino H, Salvi S, Regan JW. Differential regulation of phosphorylation of the cAMP response element-binding protein after activation of EP2 and EP4 prostanoid receptors by prostaglandin E2. Mol Pharmacol. 2005;68(1):251-259.

38. Birrell MA, Nials AT. At last, a truly selective EP(2) receptor antagonist. Br J Pharmacol. 2011; 164(7):1845-1846.

39. Codarri L, et al. ROR $\gamma$ t drives production of the cytokine GM-CSF in helper T cells, which is essential for the effector phase of autoimmune neuroinflammation. Nat Immunol. 2011;12(6):560-567.

40. El-Behi M, et al. The encephalitogenicity of T(H)17 cells is dependent on IL-1- and IL-23-induced production of the cytokine GM-CSF. Nat Immunol. 2011;12(6):568-575

41. Kebir $\mathrm{H}$, et al. Preferential recruitment of interferon- $\gamma$-expressing TH17 cells in multiple sclerosis. Ann Neurol. 2009;66(3):390-402.

42. Brucklacher-Waldert V, Steinbach K, Lioznov M, Kolster M, Holscher C, Tolosa E. Phenotypical characterization of human Th17 cells unambiguously identified by surface IL-17A expression. J Immunol. 2009;183(9):5494-5501.

43. Huber $\mathrm{M}$, et al. IL-17A secretion by $\mathrm{CD}^{+} \mathrm{T}$ cells supports Th17-mediated autoimmune encephalomyelitis. J Clin Invest. 2013;123(1):247-260.

44. Marson A, et al. Foxp3 occupancy and regulation of key target genes during T-cell stimulation. Nature. 2007;445(7130):931-935.

45. Xiao S, et al. Small-molecule ROR $\gamma$ t antagonists inhibit $\mathrm{T}$ helper 17 cell transcriptional network by divergent mechanisms. Immunity. 2014; 40(4):477-489. 